\title{
PLANOS DIRETORES MUNICIPAIS E O ZONEAMENTO URBANO: UMA ANÁLISE DA (DES) ARTICULAÇÃO ENTRE OS INSTRUMENTOS DE PLANEJAMENTO TERRITORIAL NO ENTORNO DO RESERVATÓRIO DE SALTO GRANDE (SP)
}

\section{Municipal Master Plans and urban zoning: an analysis of the (dis)articulation between the instru- ments of territorial planning in the area surrounding Salto Grande Reservoir (SP)}

\author{
Marcelo Fernando Fonseca \\ Aluno do Doutorado em Geografia, UNICAMP \\ Bolsista FAPESP \\ marcelo.fonseca@ige.unicamp.br
}

Lindon Fonseca Matias

Professor Doutor, Departamento de Geografia, UNICAMP

lindon@ige.unicamp.br

Artigo recebido em 24/07/2012 e aceito para publicação em 28/11/2012

RESUMO: A demanda por instrumentos que auxiliem no trato das tensões sociais no espaço urbano se torna cada vez mais latente ao passo em que as cidades se configuram em palco de embates entre os diversos agentes sociais, o que origina, muitas vezes, marcantes desigualdades socioespaciais. No intuito de compreender esta relação no entorno do reservatório de Salto Grande (SP), em área localizada nos municípios de Americana, Nova Odessa e Paulínia, Estado de São Paulo, faz-se neste trabalho uma análise dos Planos Diretores Municipais vigentes dessas cidades, através de seus aspectos institucionais e da política de zoneamento urbano pré-definida para cada município, avaliando a sua condição de articulação e integração, enquanto hipótese de constituição de um instrumento norteador do planejamento de uma área comum. Para o desenvolvimento de tal proposta e,como suporte analítico, foram utilizadas técnicas de geoprocessamento para omanuseio de uma base de dados geográficos egeração de mapas temáticos.Os resultados apontam para a existência de uma desarticulaçãonas diretrizes do zoneamento urbano, particularmente quando avaliadosno âmbito regional do planejamento da área, o que poderá ocasionar, em um curto espaço de tempo, relevantes conflitos de uso e ocupação da terra no entorno do reservatório.

Palavras-chave: Planos Diretores Municipais, zoneamento urbano,conflitos nos usos da terra, geoprocessamento, reservatório de Salto Grande.

ABSTRACT: The demand for tools that assist in dealing with social tensions in the urban space has become increasingly latent whereas the cities figure as the scene of conflicts among a number of social agents, which often leads to remarkable socio-spatial inequalities. In order to understand this relation in the vicinity of Salto Grande reservoir (SP), in an area located in the cities of Americana, Nova Odessa and Paulínia, in Sao Paulo State, this study analyzes the current municipal master plans of these cities, through their institutional aspects and urban zoning policy pre-defined for each city, assessing their coordination and integration conditions, while the hypothesis of establishing an instrument to guide a common area planning. For the development of such proposal, as well as an analytical support, we used geoprocessing techniques in order to handle a geographic database and generate thematic maps. The results indicate the existence of a disarticulation in the zoning guidelines, particularly when evaluated in the regional planning area, which may result in short-term relevant conflicts of use and occupancy of the land around the reservoir. Keywords: Municipal Master Plans, urban zoning, conflicts of land use, geoprocessing, Salto Grande reservoir. 


\section{INTRODUÇÃO}

A elaboração e utilização dos chamados planos diretores para nortear o desenvolvimento no âmbito municipal brasileiro não é prática recente, embora nos últimos anos tenha recebido maior destaque dentro do contexto do planejamento das cidades, sobretudo após a entrada em vigor da lei federal n. 10.257, de 2001, também conhecida como Estatuto da Cidade.

Com o intuito de avaliar aspectos específicos contidos neste instrumento político de planejamento territorial, face sua importância para os municípios, estabelecemos como ponto de partida para nosso estudo o recorte geográficocompreendendo uma área localizada em três municípios limítrofes do Estado de São Paulo, pertencentes à Região Metropolitana de Campinas (RMC): Americana, Nova Odessa e Paulínia; é justamente em áreas administradas por estas cidades que se encontra o reservatório de Salto Grande, originado a partir do represamento do rio Atibaia e da construção da barragem da usina hidrelétrica de pequeno porte inaugurada em 1949, com sede em Americana,atualmente sob a responsabilidade da Companhia Paulista de Força e Luz (CPFL).

Aárea de interesse, no entorno do reservatório, é delimitada no município de Americana pelos limites com a rodovia Anhanguera (sul) e municipais (leste/ oeste/norte); no município de Nova Odessa, a área é delimitada pela Rodovia Anhanguera e Estrada Municipal PLN-040 (sul), limite municipal com Paulínia (leste), e divisas municipais com Americana (norte/ oeste); no município de Paulínia, a área é delimitada pelas divisas municipais com Nova Odessa (oeste), Americana (norte), Estrada Municipal PLN-040 (sul) e divisores de água (leste), sendo somente esta a área a ser avaliada nesta pesquisa, conforme a Figura 1.

A área territorial considerada abrange aproximadamente $90 \mathrm{~km}^{2}$ nos três municípios, sendo que o reservatório em si apresenta um comprimento máximo de $17 \mathrm{~km}$ e uma profundidade média de $8 \mathrm{~m}$, com seu valor máximo em torno de $20 \mathrm{~m}$; a área inundada mínima é de $10,55 \mathrm{~km}^{2}$ e a área máxima de inundação é de 13,25 km²(LEITE, 2002).Apesar de apresentar grande potencial recreacional, as águas do reservatório estão sujeitas a ocorrência frequente de florações de algas e odores ruins, que comprometem tais tipos de atividades (PCJ, 2006), estando este uso restrito atualmente a alguns proprietários de lotes nas margens da represa, possuidores de pequenas embarcações.

Com relação ao histórico de uso e ocupação da terra no entorno do reservatório, as primeiras construções, sobretudo de residências e chácaras de veraneio, datam do ano de 1951 (PMA, 2010a); desde então, um significativo processo de urbanização vem ocorrendo na área, com ênfase para a porção oeste localizada no município de Americana, onde inúmeros bairros já consolidados demarcam uma área densamente ocupada.Em contrapartida, principalmente ao norte do reservatório, encontram-se grandes porções territoriais ocupadas por cultivos agrícolas, em especial a cana-de-açúcar, comumente em terras arrendadas de proprietários particulares. 
Figura 1. Localização do reservatório de Salto Grande e o entorno considerado

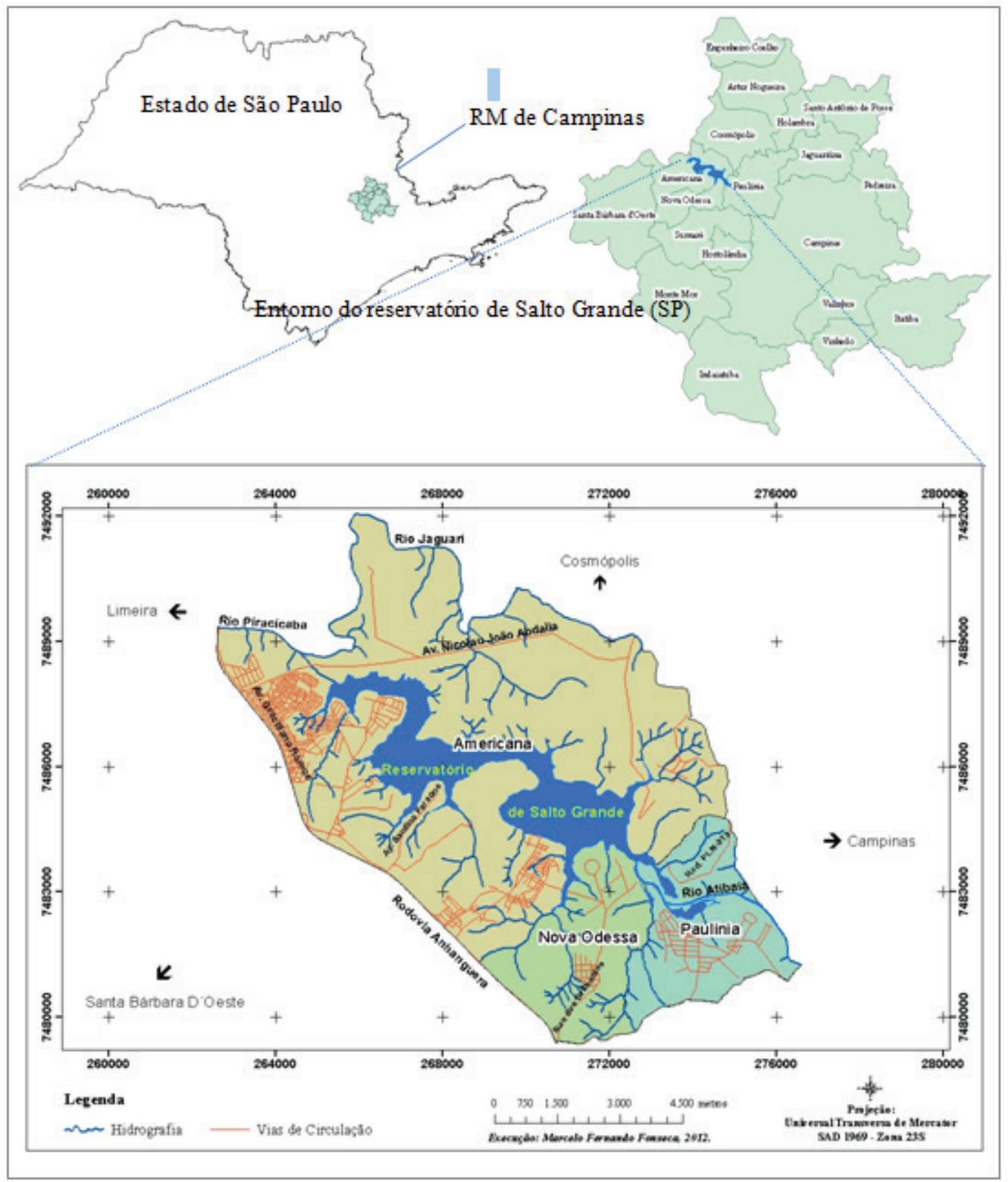

Org. dos autores.

Os três municípios diretamente envolvidos com o planejamento da área tiveram os seus Planos Diretores Municipais revisados recentemente; cabe lembrar que, embora tais planos já fizessem parte do contexto das grandes e médias cidades nas décadas de 1960 e 1970, é somente com a promulgação da Constituição de 1988 e a inclusão do capítulo de Política Urbana no texto constitucional (artigos 182 e 183) e, posteriormente, com a aprovação do Estatuto da Cidade (Lei Federal n. 10.257/2001), que tais instrumen- tos passam a adquirir uma função verdadeiramente estratégica ao nortear a política de desenvolvimento e expansão urbana que necessariamente deve ser regulamentada por lei municipal (CYMBALISTA; SANTORO,2009), inclusive com a obrigatoriedade do instrumento em municípios de menor porte.

Nesta linha de raciocínio, o Estatuto da Cidade estabeleceuprazos, expirado em 2006, para que todos os municípios com mais de vinte mil habitantes elaborassem seus planos diretores; ao Ministério das 
Cidades, criado em 2003, recaiu o compromisso de disseminar as práticas legais e a capacitação para a elaboração ou revisão dos chamados Planos Diretores Participativos, com o objetivo de garantir o envolvimento de todos os segmentos sociais nas discussões envolvendo as diretrizes de tais planos, tornando-os fruto de uma participação popular mais efetiva; a este mesmo Ministério coube, ainda, a convocação da primeira Conferência Nacional das Cidades, em 2003, de onde se originaram as raízes para a formação do Conselho das Cidades, que posteriormente aprovaria as propostas das políticas nacionais de habitação, saneamento ambiental, trânsito, mobilidade e transporte urbano (MARICATO, 2006, p. 216).

Sem a pretensão de analisar os planos diretores detalhadamente em sua composição total, interessa-nos neste trabalho, em particular, analisar um item de destaque dentro de seu contexto geral: os capítulos e/ou seções relacionados ao zoneamento urbano, inseridos sob os títulos de "ordenamento territorial"nos planos de Americana e Paulínia e sob o título de "plano urbanístico e ordenamento do território", no plano diretor de Nova Odessa.

Segundo Villaça (1995, p. 45), entende-se por zoneamento "[...] a legislação urbanística que divide em zonas toda a área urbana e de expansão urbana dos municípios, sendo que para cada uma a lei define: o coeficiente máximo de aproveitamento dos terrenos, a taxa máxima de ocupação dos terrenos e, finalmente, os usos permitidos e proibidos na zona"; ainda segundo o autor, o zoneamento urbano, atualmente parte integrante de qualquer plano diretor, não deve ser confundido com o mesmo, pois foi, historicamente, implantado muitas vezes de forma independente através de lei específica.

Mesmo com as possibilidades de intervenção em muito ampliadas pelos novos mecanismos legais, como o Estatuto da Cidade, nos parece que a maior parte das prefeituras municipais continua a propagar em seus Planos Diretores de desenvolvimento, sobretudo no que diz respeito às especificidades do zoneamento urbano, as propostas que simplesmente regulamentam usos e atividades no território da forma mais tradicional possível, ou seja, com pouca inovação e atribuindo a estes espaços uma qualificação nem sempre adequada, ou simplesmente impondo
restrições.Muitas vezes, não deixam claro o porquê destas escolhas, nem tampouco apresentam estudos que avaliem as implicações de tais zoneamentos.

Com a pretensão de avaliar com mais detalhes a área do entorno do reservatório de Salto Grande (SP), cuja área perpassa o território de três municípios limítrofes e, portanto, coloca em xeque as discussões acerca da necessidadede uma gestão territorial conjunta, é que buscamos neste trabalho reunir informações a respeito dos Planos Diretores Municipais de Americana, Nova Odessa e Paulínia, analisando se o zoneamento urbano proposto por cada ente municipal se apresenta compatível quando avaliado sob a perspectiva integrada para a área; o que se objetivaé a tarefa de investigar a existência ou não de uma articulação entre estes importantes instrumentos de planejamento territorial.

\section{PROCEDIMENTOS METODOLÓGICOS}

Como referência inicial, buscou-se na legislação municipal o amparo legal para a realização das análises, através do levantamento das últimas revisões dos Planos Diretores dos municípios envolvidos e do levantamento das diretrizes de zoneamento definidas previamente para o entorno do reservatório de Salto Grande.

O município de Americana, responsável pela gestão da maior porção territorial dentro do recorte selecionado (74,39\% do total da área, com $67,28 \mathrm{~km}^{2}$ ), apresenta o Plano Diretor revisado mais recentemente, do ano de 2008 (lei municipal n. 4.597), o qual instituiu, a partir de sua política de ordenamento territorial, duas grandes Macrozonas para o planejamento do município: a Macrozona de Uso PredominanteUrbano (MPU) e a Macrozona de Uso Predominante Ambiental (MPA). A primeira inclui toda a porção urbanizada ao sul do reservatório de Salto Grande e a última inclui a área localizada ao norte,também classificada como APAMA (Área de Proteção Ambiental Municipal de Americana), onde se encontramglebas de proprietários distintos, propriedades particulares, algumas arrendadas paracultivosextensivos, propriedades municipais e estaduais, além de loteamentos residenciais a serem regularizados (PMA, 2010b). Quanto ao zoneamento,entendido pelo poder público como a 
subdivisão das áreas de uma macrozona (PDDI, 2008), foram identificadas 39 subdivisões relacionadas ao zoneamento urbano,somente na área de estudo, sendo possível agrupar estas em categorias específicas, o que resulta em 13 zonas diferentes quanto a sua tipificação.

Já em Nova Odessa, responsável por 11,63 km² ou $12,86 \%$ da área avaliada no entorno do reservatório, o Plano Diretor Participativo, revisado e aprovado no ano de 2006 (lei complementar n.10),determina a partir de sua política de ordenamento territoriala subdivisão da área de estudo em 02 grandes zonas dentro deste município, que foram então analisadas.
Por fim, no município de Paulínia, representando 11,53 $\mathrm{km}^{2}$ ou $12,75 \%$ da área avaliada e com o respectivo Plano Diretor revisado e aprovado também em 2006 (lei municipal n. 2.852), aparece na área de estudo um total de 04 subdivisões relacionadas ao zoneamento urbano, das quais após agrupadas segundo sua tipificação, resultam em 03 zonas diferentes. A Tabela 1 apresenta uma síntese das informações, de acordo com a nomenclatura utilizada para cada zona e em cada plano diretor avaliado.

Tabela 1. Descrição das áreas delimitadas segundo o zoneamento urbano

\begin{tabular}{|c|c|c|c|}
\hline Município & $\begin{array}{c}\text { Referência ao } \\
\text { Zoneamento no } \\
\text { Plano Diretor }\end{array}$ & Sigla & Descrição \\
\hline \multirow{13}{*}{$\begin{array}{c}\text { Americana } \\
\text { (Lei N. } 4.597 \text { - } \\
01 / 02 / 2008)\end{array}$} & \multirow{9}{*}{$\begin{array}{c}\text { MPU - } \\
\text { MACROZONA } \\
\text { DE USO } \\
\text { PREDOMINANTE } \\
\text { URBANO }\end{array}$} & ZAE1 & Zona de Atividade Econômica 1 \\
\hline & & ZAE2 & Zona de Atividade Econômica 2 \\
\hline & & ZAE3 & Zona de Atividade Econômica 3 \\
\hline & & ZR1 & Zona Residencial 1 \\
\hline & & ZR2 & Zona Residencial 2 \\
\hline & & $\mathrm{ZM}$ & Zona Mista \\
\hline & & UAIU & Unidade de Área de Interesse Urbanístico \\
\hline & & UZEIS & Unidade de Zona Especial de Interesse Social \\
\hline & & UAV & Unidade de Área Verde \\
\hline & \multirow{4}{*}{$\begin{array}{c}\text { MPA - } \\
\text { MACROZONA } \\
\text { DE USO } \\
\text { PREDOMINANTE } \\
\text { AMBIENTAL }\end{array}$} & Z-I-ZPR & Zona de Preservação e Recuperação \\
\hline & & Z-II-ZPH & Zona de Preservação e Moradia Horizontal \\
\hline & & Z-III-ZPE & Zona de Preservação e Atividades Econômicas \\
\hline & & Z-IV-ZPM & Zona de Preservação e Moradia \\
\hline \multirow{2}{*}{$\begin{array}{c}\text { Nova Odessa } \\
\text { (Lei Compl. N.10 - } \\
06 / 10 / 2006)\end{array}$} & \multirow{2}{*}{$\begin{array}{c}\text { DA ESTRUTURA } \\
\text { URBANA }\end{array}$} & ZPI-1 & Zona de Produção Industrial \\
\hline & & ZPATR & Zona de Produção Agrícola, Turismo e Recreação \\
\hline \multirow{3}{*}{$\begin{array}{c}\text { Paulínia } \\
\text { (Lei N. 2.852 - } \\
\text { 22/12/2006) }\end{array}$} & \multirow{3}{*}{$\begin{array}{c}\text { DO } \\
\text { ZONEAMENTO }\end{array}$} & ZE & Zona de Especial Proteção \\
\hline & & ZR1 & $\begin{array}{l}\text { Zona Predominante Residencial de Baixa } \\
\text { Densidade }\end{array}$ \\
\hline & & ZR3 & $\begin{array}{l}\text { Zona Predominante Residencial de Média } \\
\text { Densidade }\end{array}$ \\
\hline
\end{tabular}

Org. dos autores

Após a identificação preliminar do zoneamento urbano estabelecido por legislação municipal para o entorno do reservatório de Salto Grande, levantou-se as características particulares permitidas ou proibitivas de uso e ocupação, definidas segundo as normas para cada zona, objetivando, sobretudo, a análise dentro da escala intermunicipal, ou seja, na faixa limítrofe entre os municípios já citados. Como abordado por Freitas (2007, p. 91), "ao se analisarem as dinâmicas que se impõe e modificam o território municipal, visando 
subsidiar a definição do zoneamento, devem-se considerar abrangências e escalas territoriais mais amplas e necessariamente intermunicipais". O mesmo autor complementa que tal recomendação se dá em virtude da necessidade de "verificar a existência de condições similares e igualmente desejáveis nos setores vizinhos dos municípios com os quais se limita, sob pena de estabelecer restrições inócuas em face de evidentes pressões que tendem a se desenvolver e mesmo aumentar muito com o tempo a partir de contextos externos ao território municipal".

De posse destes dados e de material complementar digital contendo os limites territoriais de cada zona em seu respectivo município, optamos por utilizar o software de análise espacial ArcGIS ${ }^{\circledR}$ em sua versão 10 (ESRI, 2010) para a elaboração de uma base de dados cartográfica com a premissa de extrair novas informações, através da aplicação de algumas técnicas associadas ao geoprocessamento. Imagens orbitais do ano de 2010, originadas do satélite japonês ALOS (Advanced Land ObservingSatellite), que apresenta resolução espacial de $2,5 \mathrm{~m}$, além de fotografias aéreas do ano de 2008, apresentando resolução espacial superior, também foram utilizadas como suporte e inseridas na base de dados. O uso destes recursos, associados aos Sistemas de Informação Geográfica (SIG), vem sendo popularizados desde a década de 1990 como instrumentos auxiliares para a tomada de decisão (BOLFE; MATIAS; FERREIRA; 2008), cabendo ao pesquisador o rigor científico em seu uso e a necessária assimilação das técnicas e conceitos que os cercam.

Com a integração dos dados através destes procedimentos, foi possível constituir uma plataforma base de informações voltadas para a investigação analítica sobre a existência ou não de articulação entre os respectivos planos diretores municipais, no que concernem especificamente as diretrizes do zoneamento de uso e ocupação da terra.

\section{RESULTADOS E DISCUSSÃO}

Apesar de suas limitações e da ampla discussão a respeito, principalmente acerca de suas implicações políticas e sociais (CINTRA, 2006), o zoneamento urbano, entendido como mais um dentre os muitos instrumentos a serviço do planejamento territorial, deve ser derivado de um estudo detalhado dos usos atuais da terra e de temas correlatos, considerando inclusive as tendências da evolução urbana de cada município envolvido e sua interação com as ações de uma gestão urbana ampliada.

A partir da inserção e do tratamento dos dados geográficos obtidos para este estudo em ambiente computacional, fez-se usodos recursos e técnicas de geoprocessamento para se calcular a área total correspondente, em $\mathrm{km}^{2}$ e proporcionalmente,destinada a cada subdivisão do zoneamento urbano, segundo os critérios dos planos diretores municipais e de acordo com as especificidades de uso, e os valores encontrados para o entorno do reservatório de Salto Grande são apresentados na Tabela 2.

Soc. \& Nat., Uberlândia, 25 (1): 61-74, jan/abr/2013 
Planos Diretores Municipais e o zoneamento urbano: uma análise da (des)articulação entre os instrumentos de planejamento territorial no entorno do Reservatório de Salto Grande (SP) Marcelo Fernando Fonseca, Lindon Fonseca Matias

Tabela 2. Divisão por zonas e cálculo das respectivas áreas em cada município

\begin{tabular}{|c|c|c|c|c|c|}
\hline Município & $\begin{array}{l}\mathrm{N}^{\circ} \text { de áreas } \\
\text { distribuídas } \\
\text { no entorno }\end{array}$ & Sigla & Descrição & $\begin{array}{c}\text { Área total } \\
\left(\mathbf{k m}^{2}\right)\end{array}$ & $\begin{array}{c}\text { Área total } \\
(\%)\end{array}$ \\
\hline \multirow{13}{*}{ Americana } & 2 & ZAE1 & Zona de Atividade Econômica 1 & 0,08 & 0,10 \\
\hline & 7 & ZAE2 & Zona de Atividade Econômica 2 & 3,80 & 4,72 \\
\hline & 1 & ZAE3 & Zona de Atividade Econômica 3 & 0,65 & 0,81 \\
\hline & 1 & ZR1 & Zona Residencial 1 & 8,25 & 10,25 \\
\hline & 5 & ZR2 & Zona Residencial 2 & 1,13 & 1,40 \\
\hline & 5 & ZM & Zona Mista & 6,28 & 7,80 \\
\hline & 4 & UAIU & Unidade de Área de Interesse Urbanístico & 1,03 & 1,28 \\
\hline & 6 & UZEIS & Unidade de Zona Especial de Interesse Social & 0,47 & 0,59 \\
\hline & 4 & UAV & Unidade de Área Verde & 3,80 & 4,72 \\
\hline & 1 & Z-I-ZPR & Zona de Preservação e Recuperação & 7,25 & 9,00 \\
\hline & 1 & Z-II-ZPH & Zona de Preservação e Moradia Horizontal & 8,51 & 10,58 \\
\hline & 1 & Z-III-ZPE & Zona de Preservação e Atividades Econômicas & 12,80 & 15,90 \\
\hline & 1 & Z-IV-ZPM & Zona de Preservação e Moradia & 4,04 & 5,02 \\
\hline \multirow{2}{*}{ N. Odessa } & 1 & ZPI-1 & Zona de Produção Industrial & 6,08 & 7,55 \\
\hline & 1 & ZPATR & Zona de Prod. Agrícola, Turismo e Recreação & 4,81 & 5,98 \\
\hline \multirow{3}{*}{ Paulínia } & 1 & $\mathbf{Z E}$ & Zona de Especial Proteção & 1,93 & 2,40 \\
\hline & 1 & ZR1 & Zona Pred. Residencial de Baixa Densidade & 5,57 & 6,92 \\
\hline & 2 & ZR3 & Zona Pred. Residencial de Média Densidade & 4,01 & 4,98 \\
\hline TOTAL & 45 & - & - & 80,49 & 100,00 \\
\hline
\end{tabular}

Org. dos autores.

Buscando uma síntese destes dados, procedeu-se o agrupamento das áreas apresentadas anteriormente em cinco grandes eixos principais, com base em sua característica primordial e considerando o quesito uso e ocupação da terra, estabelecido pelo zoneamento urbano, a saber: Zona de Atividade Econômica (ZAE),
Zona Residencial (ZR), Zona Mista (ZM), Unidade de Área de Interesse Urbanístico (UAIU) e Unidade de Área Verde / Preservação e Recuperação (UAV), obtendo o seguinte gráfico para a área de estudo em sua totalidade.

Figura 2. Agrupamento de áreas com base em sua característica principal quanto ao uso e ocupação da terra, estabelecido pelo zoneamento urbano

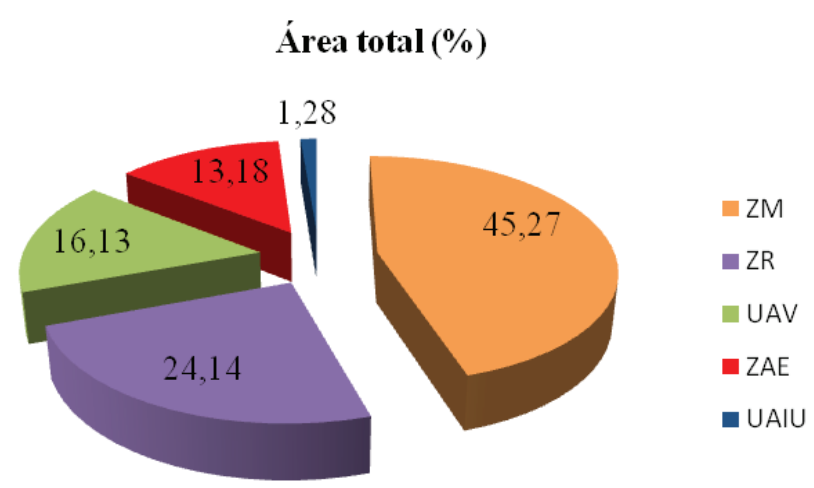

Org. dos autores. 
A análise conjunta para os três municípios - Americana, Nova Odessa e Paulínia -mostra que $45,27 \%$ da área está classificada, no contexto do zoneamento urbano, como Zona Mista (ZM), o que engloba a possibilidade dos usos residencial, institucional, comercial e de serviços, atividades agropecuárias e industriais de pequeno porte, além de áreas de preservação, turismo e recreação. As áreas destinadas exclusivamente ao uso residencial (ZR) chegam a quase $1 / 4$ da área $(24,14 \%)$, e se considerarmos que nas Zonas Mistas também poderemos ter o uso residencial, quase $70 \%$ da área pode legalmente ser ocupada no futuro para este fim; somando-se aos $13,18 \%$ destinados para fins de atividades econômicas industriais, inclusive comportando empresas de grande porte, pode-se aferir a importância de um planejamento adequado para gerir esta ocupação. Sobre a Unidade de Área de Interesse Urbanístico (UAIU), prevista a ocupar apenas 1,28\% da área, trata-se de área incluída somente no zoneamento do município de Americana, sendo composta por "espaços especiais de preservação urbanística, arquitetônica e/ou paisagística" (PDDI, 2008).

Estes dados corroboram para justificar a enorme potencialidade da área como lócus de expansão urbana, para os três municípios citados e, frente a esta possibilidade, nos dedicamos a analisar com mais detalhes a articulação entre o zoneamento urbano nas áreas limítrofes destes municípios, buscando investigar, sob a ótica da gestão intermunicipal, a existência de possíveis conflitos que podem eventualmente ser gerados a partir das definições contidas nos respectivos planos diretores municipais.

Segundo Freitas (2007, p 91), "pode-se ilustrar esta questão a partir de casos em que, por exemplo, defina-se zona de uso industrial com limites comuns aos de eventual zona compreendendo unidades de proteção integral (como parques ou reservas florestais) estabelecida no Plano Diretor do município vizinho", sendo este um exemplo de grave desarticulação entre os instrumentos aplicáveis para fins de planejamento territorial, estabelecidos pelos municípios limítrofes, quando estes representam apenas os interesses isolados de cada município.

Para realizar a análise em questão, gerou-se também o mapa da Figura 3, contendo a divisão estabelecida pelo zoneamento urbano de cada município, o que propiciou o estudo e a compreensão do componente espacial dos dados.

Em termos gerais, chama a atenção, primeiramente para o município de Americana, a presença ao norte do reservatório de uma grande área, com aproximadamente $32 \mathrm{~km}^{2}$ (PDPR, 2004) subdividida em 04 grandes zonas. A relevância desta área, maior do que a ocupada efetivamente na margem esquerda do reservatório, é percebida ao se fazer a leitura do próprio Plano Diretor do município, que a coloca "como área de expansão da malha urbana e de reserva ambiental"; o documento estabelece ainda como meta "a realização de estudos complementares para a área, através de regulamentação específica em lei” (PDDI, 2008, p. 14). Espera-se que estes estudos complementares contemplem um zoneamento urbano bem mais detalhado que o vigente atualmente, que nos parece muito generalista e pouco amplo em suas especificações de uso da terra.

O mesmo fato se observa para o município de Nova Odessa, onde o zoneamento estabelecido para a área no entorno do reservatório faz menção a somente duas grandes áreas (ZPI-1 e ZPATR), um pouco generalistas em suas especificações, cobrindo uma grande extensão territorial, superior a $10 \mathrm{~km}^{2}$. Já dentro dos limites do município de Paulínia, o que chama a atenção é a preponderância dada pela legislação do zoneamento à instalação de futuras áreas residenciais no entorno do reservatório. 
Figura 3. Zoneamento urbano municipal - Americana, Nova Odessa e Paulínia

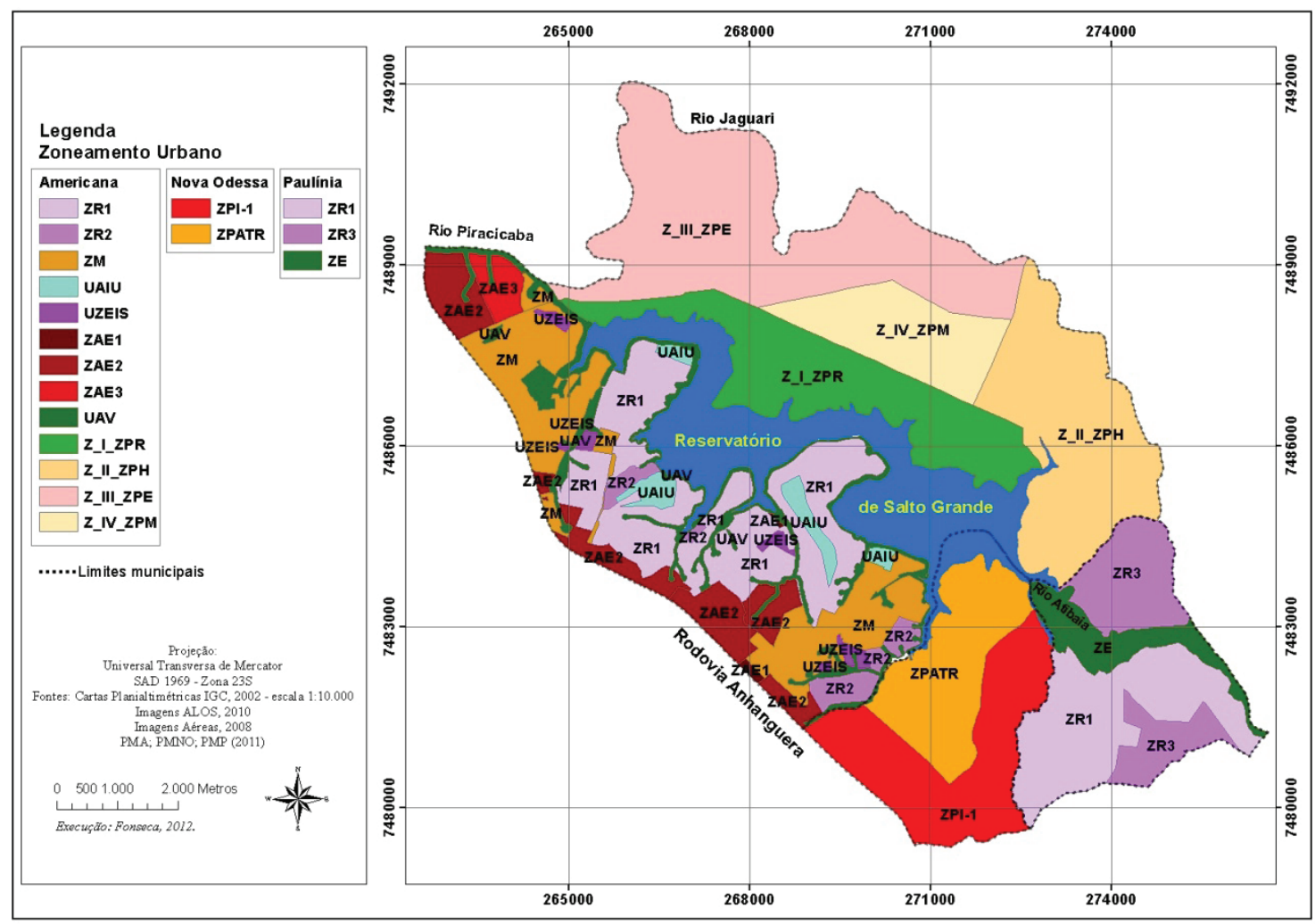

Org. dos autores.

Saindo do quadro geral e entrando nas análises envolvendo as particularidades e articulações do zoneamento urbano nas áreas limítrofes destes municípios, avaliamos algumas áreas espacialmente contíguas, mas que apresentam planejamentos de uso diferenciados, de acordo com a égide de cada municipalidade envolvida. A seguir, estas análises são apresentadas em tópicos separados e comentadas individualmente.

\section{ZPI-1 (Nova Odessa) xZAE2 eZR2 (Americana)}

A Zona de Produção Industrial (ZPI-1) demarca uma grande área em Nova Odessa onde há "o interesse público em promover a atividade industrial" (PD, 2006); já no município de Americana, fazendo limite com esta área, encontra-se junto à rodovia Anhanguera uma faixa classificada pelo zoneamento como Zona de Atividade Econômica 2 (ZAE2), o que implica em dizer que ambos os usos mostram- -se compatíveis.Porém, prosseguindo no sentido do reservatório, ainda no limite com Nova Odessa, o zoneamento urbano em Americana estabelece áreas destinadas ao uso residencial (ZR2), o que requer cuidados com o tipo de atividade industrial a ser permitida neste limite, sob condição de gerar potencial conflito em termos de uso da terra.

Em Americana já existe um grande contingente populacional presente na Zona Mista (ZM), próximo da divisa com Nova Odessa, além de duas Unidades de Zoneamento de Especial Interesse Social (UZEIS), que se juntariam no futuro a estas previstas Zonas Residenciais (ZR2).

Em Nova Odessa, o que parece configurar uma situação de conflito é que esta zona ZPI-1 se estende para norte, a partir do limite com a rodovia Anhanguera, até os limites com o próprio reservatório o que, supostamente, se considerarmos a implantação de indústrias dos mais variados portes, pode acarretar impactos de grande proporção para a represa e seu entorno, em um cenário regional já 
comprovado de degradação e crescente emissão de carga industrial nos corpos hídricos da sub-bacia do Atibaia (LOPES et al., 2004). Por outro lado, um ponto positivo verificado no plano diretor deste município é a questão referente à realocação de indústrias em casos graves de infração ambiental ou de outra natureza, embora a localização da ZPI-1 logo no "início"do reservatório, próximo à desembocadura do rio Atibaia, deva ser desencorajada, como forma de prevenção a possíveis impactos socioambientais.

\section{ZPATR (Nova Odessa) x ZR2 (Americana)}

Fazendo divisa com os limites das futuras áreas residenciais definidas por Americana (ZR2), o zoneamento presente no plano diretor de Nova Odessa define uma grande área como Zona de Produção Agrícola, Turismo e Recreação (ZPATR), o que se pela nomenclatura utilizada já deixa dúvidas quanto a sua amplitude de ocupação,ao observar a descrição das possibilidades de uso da terra na legislação, esta se mostra bem extensiva, pois permite amplamente diversos tipos de ocupação, como atividades agrícolas, pecuária, extração mineral e atividades de lazer, além de residências, hotéis e vários tipos e portes de comércio e serviços (PD, 2006).

Se não for definida com mais clareza e precisão o zoneamento urbano para esta grande área, certamente corre-se o risco de ser ocupada de forma desordenada e trazer sérios problemas ao reservatório e seu entorno, constituindo-se, portanto, em potencial área de conflito de uso da terra.

Um fato importante a se destacar é que entre as divisas municipais de Americana e Nova Odessa existem relevantes fragmentos de vegetação cuja preservação torna-se prioritária diante de um quadro crescente de degradação destes espaços.

\section{ZPI-1 (Nova Odessa) x ZR1 (Paulínia)}

Uma grande faixa limítrofe de aproximadamente 3,5 km separa estas duas zonas, que estabelecem usos opostos: em Nova Odessa, a Zona de Produção Industrial (ZPI-1) ocuparia futuramente, de acordo com o zoneamento, uma área onde hoje se encontra predominantemente fragmentos florestais dispersos; pelo lado de Paulínia, a ocupação prevê uma zona predominantemente residencial de baixa densidade (ZR1), estabelecendo a área mínima do lote em $600 \mathrm{~m}^{2}$. Se não houver a constituição de uma zona de transição entre estes dois espaços, há o risco da ocorrência de futuros conflitos e/ou possíveis tensões entre esses usos afetando, sobretudo, a população permanente.

\section{ZR3 (Paulínia) $x$ Z_II_ZPH (Americana)}

Em Paulínia, com exceção de uma Zona de Especial Proteção (ZE) localizada às margens do rio Atibaia, formador do reservatório de Salto Grande, são definidas somente zonas residenciais (ZR1 e ZR3), o que pode implicar em grande pressão antrópica no entorno do reservatório. Além disso, no limite com Americana, estará em contato com a Zona de Preservação e Moradia Horizontal (Z_II_ZPH), uma grande área onde o zoneamento estabelece, ainda de forma genérica, o uso habitacional horizontal, com comércio e serviços do tipo local, garantindo também a adoção de medidas de preservação em locais a serem levantados e determinados por estudos complementares.

Pelas diretrizes dos respectivos planos diretores municipais, percebe-se que podem representar uma continuidade no tipo de zoneamento; aparentemente, o que seria uma boa solução, esconde a grande pressão antrópica que pode vir a ocorrer no entorno do reservatório, o que sem dúvida demandaria esforços em medidas mitigadoras; no município de Americana, inclusive, está localizado nesta área um dos maiores remanescentes florestais de todo o entorno do reservatório, com aproximadamente $0,85 \mathrm{~km}^{2}$, o que exige estudos preliminares antes de qualquer ocupação, visando a sua manutenção.

Outros dois fatos concretos justificam a preocupação com a crescente pressão antrópica nesta área limítrofe e a falta de planejamento e infraestrutura para suportar tais demandas: na chamada Z_II_ZPH, localiza-se um loteamento denominado de Recanto das Águas considerado, segundo levantamentos desta pesquisa, irregular pela Prefeitura Municipal de Americana, cuja população moradora carece de melhores condições de acesso a serviços básicos e indispensá- 
veis e reivindica, inclusive, a sua incorporação ao município de Paulínia (TODO DIA, 2007; TVB, 2010), o que caracteriza um conflito em andamento. Já pelo lado de Paulínia, um novo loteamento aprovado recentemente e constituído por conjuntos habitacionais de interesse social na região conhecida como Saltinho, localizado a pouco mais de $1 \mathrm{~km}$ do reservatório, traz a mesma preocupação. Extremamente importantes do ponto de vista social, estas áreas visam "promover a ampliação do acesso ao mercado habitacional formal para a população de baixa renda" (FREITAS, 2007, p. 90), mas sua localização próxima ao reservatório e distante de centros comerciais do município devem demandar outras necessidades e intervenções, as quais precisam ser abraçadas pelo poder público.

Concluindo a avaliação envolvendo o zoneamento urbano proposto pelos três municípios em questão para o entorno do reservatório de Salto Grande, observa-se que, embora tais instrumentos tenham sido elaborados a partir de revisões recentes dos planos diretores municipais, aparentemente não houve uma avalição da articulação regional entre os mesmos e, na hipótese disso ter ocorrido no momento de sua regulamentação, não há indícios de que possam ter atendido com clareza e efetividade a premissa necessária desta integração.

Ressalta-se, assim, a necessidade de convergência das ações entre os agentes sociais envolvidos com a elaboração destes planos, buscando conduzir, de forma integrada, sustentável e socialmente justa, inicialmente o planejamento e, posteriormente, a gestão para uma área de interesse comum, como é o caso do entorno do reservatório. É preciso uma articulação intermunicipal a fim de maximizar os recursos e evitar possíveis conflitos de uso da terra que a qualquer momento podem eclodir com significativa intensidade na área de estudo.

\section{CONSIDERAÇÕES FINAIS}

As proposições deste trabalho de pesquisa apontam para a necessidade de algumas reflexões sobre o zoneamento urbano dos municípios citados, mais especificamente revisando as diretrizes deste instrumento de planejamento. Não por acaso, as discussões envolvendo tais instrumentos compreendem comumente, como analisa Braga (2001, p. 104), a diversidade de interesses tanto dos agentes públicos, que teoricamente são os incumbidos pela defesa da coletividade, quanto os interesses dos agentes privados, baseados muitas vezes na especulação imobiliária e no mercado de terras. O mesmo autor lembra, ainda, que "quando se dispõe sobre as atividades urbanas, está se dispondo sobre as pessoas, ou melhor, sobre os grupos sociais que exercem estas atividades", o que exige, ao se tratar do tema, total imparcialidade, evitando que o mesmo se torne "um instrumento de segregação socioespacial".

Em termos pontuais, para o município de Americana, é importante reavaliar o zoneamento para a área ao norte do reservatório, mesmo caso do município de Nova Odessa, onde uma nova leitura para $\mathrm{a}$ área destinada às atividades de produção industrial poderia ser pertinente, evitando generalizações e valorizando a adoção de usos múltiplos. Em Paulínia, sugere-se especial atenção em relação às demandas geradas pela crescente implantação de novas unidades habitacionais, já que esta expansão vem acontecendo em um ritmo muito acelerado.

Por fim, não podemos também cair na armadilha de entender o zoneamento simplesmente como um instrumento homogeneizador do espaço urbano, através da simples compartimentação de espaços funcionais, visto que a complexidade das cidades não comporta tal ideia reducionista. Tratando-se o zoneamento de importante instrumental para o planejamento, é preciso, sobretudo, aprimorar os mecanismos de participação em sua elaboração, pois com a atuação dos agentes sociais,como afirma Maricato (2000, p. 180), "é possível criar uma esfera ampla de debate e legitimar os participantes com seus pontos de vista diferentes e conflitantes", dando origem assim a políticas e ações voltadas para a mitigação dos impactos nas áreas já ocupadas e que, por sua vez, podem ser indutoras de um destino mais adequado para as que apresentam elevado potencial de ocupação.

\section{AGRADECIMENTOS}

À Fundação de Amparo à Pesquisa do Estado de São Paulo (FAPESP), pela concessão da bolsa de estudos na modalidade Doutorado, através da qual 
Planos Diretores Municipais e o zoneamento urbano: uma análise da (des)articulação entre os instrumentos de planejamento territorial no entorno do Reservatório de Salto Grande (SP)

Marcelo Fernando Fonseca, Lindon Fonseca Matias

foi viabilizada a elaboração deste artigo, bem como de outros trabalhos derivados do desenvolvimento da pesquisa atualmente em andamento.

\section{REFERÊNCIAS}

BOLFE, E.L.; MATIAS, L.F.; FERREIRA, M.C. Sistemas de informação geográfica: uma abordagem contextualizada na história. Geografia. Vol. 33, n.1, Rio Claro, SP. 2008.

BRAGA, R.; CARVALHO, P. F. de. (org.) Perspectivas de gestão ambiental em cidades médias. Rio Claro: LPM-Unesp, 2001.

CINTRA, A.O. Zoneamento: análise política de um instrumento urbanístico. RBCS, Associação Nacional de Pós-Graduação e Pesquisa em Ciências Sociais (ANPOCS). São Paulo, 2006. Disponível em < www. anpocs.org.br>. Acesso em: 06 de abr. de 2012.

CYMBALISTA, R.; SANTORO, P.F. Planos Diretores: processos e aprendizados. Instituto Pólis. São Paulo. 2009. 158p.

FREITAS, C. G. L. de (coord.). Planos diretores municipais: integração regional estratégica - roteiro metodológico. Coleção Habitare. Porto Alegre: ANTAC, 2007. 184 p.

LEITE, M. A. Análise do aporte, da taxa de sedimentação e da concentração de metais na água, plâncton e sedimento do reservatório de Salto Grande, Americana - SP. Escola de Engenharia de São Carlos, USP, São Carlos, Tese de Doutorado. 2002.

LOPES, A. A. A influência do desenvolvimento econômico-industrial na degradação da qualidade da água do reservatório de Salto Grande. In: ESPÍNDOLA, E.L.G.; LEITE, M.A.; DORNFELD, C. B. Reservatório de Salto Grande (Americana, SP): caracterização, impactos e propostas de manejo. São Carlos: RIMA. 2004, 484p.

PCJ - PLANO. Plano de bacias hidrográficas 20042007 dos rios Piracicaba, Capivari e Jundiai. Relatório Final. SABESP. 2006. 770p.
PMNO - PREFEITURA MUNICIPAL DE NOVA ODESSA. Plano Diretor do município de Nova Odes$s a$. Lei complementar $\mathrm{n}^{\circ} 10$ : Institui o Plano Diretor Participativo e o Sistema de Planejamento Integrado e Gestão Participativa do Município de Nova Odessa. Nova Odessa: 06 de out. 2006.

PMP - PREFEITURA MUNICIPAL DE PAULÍNIA. Plano Diretor do município de Paulínia. Lei n ${ }^{\circ} 2.852$ : Institui o Plano Diretor do Município de Paulínia. Paulínia: 22 de dez. 2006.

PMA - PREFEITURA MUNICIPAL DE AMERICANA. Plano Diretor de Desenvolvimento Integrado município de Americana (PDDI). Lei no 4.597: Dispõe sobre o Plano Diretor de Desenvolvimento Integrado (PDDI) do Município de Americana. Americana: 01 de fev. 2008.

- Plano de Desenvolvimento Pós-Represa $(\overline{P D P R})$. Prefeitura Municipal de Americana. SEPLAN/PMA, 2004.

- Relação dos loteamentos do município de Americana. Secretaria de Planejamento - Setor de Geoprocessamento. Planilha eletrônica. 2010a.

Histórico territorial da Área de Proteção Ambiental Municipal de Americana (APAMA). Prefeitura Municipal de Americana (PMA), Secretaria de Planejamento, Unidade de Estatística e Análise Sócio-Econômica. 2010b. 9p.

MARICATO, E. As ideias fora do lugar e o lugar fora das ideias. Planejamento urbano no Brasil. In: ARANTES, O.; VAINER, C.; MARICATO, E. (org.). A cidade do pensamento único: desmanchando consensos. Petrópolis, RJ. Vozes, 2000. 192 p.

MARICATO, E. Cidades brasileiras: a matriz patrimonialista. In: O Ministério das Cidades e a Política Nacional de Desenvolvimento Urbano. Instituto de Pesquisa Econômica Aplicada (IPEA). Políticas Sociais, acompanhamento e análise, n.12. Brasília, 2006, p. 211-220. 
TODO DIA (Jornal). Moradores querem incorporação de bairro. Jornal Todo Dia. Americana/SP, 15 jan. de 2007.

TVB / TV BRASIL. Seis mil pessoas pedem a Paulinia anexar bairros de Americana e Cosmópolis. Campinas/SP, 30 jul. de 2010.

VILLAÇA, F. A crise do planejamento urbano. Revista São Paulo em Perspectiva, vol. 9, n. 2, 1995, p. 45-51. 